\title{
Pengukuran Kualitas Website Pengurus Cabang NU Depok Menggunakan Software Metric
}

\author{
Ryan Aji Wijaya ${ }^{[1]^{*}}$, Karmilasari ${ }^{[2]}$ \\ Program Studi Magister Sistem Informasi, Universitas Gunadarma ${ }^{[1], ~[2] ~}$ \\ Depok, Indonesia \\ ryan.gritoid@gmail.com ${ }^{[1]}$,karmila@staff.gunadarma.ac.id ${ }^{[2]}$
}

\begin{abstract}
The website of "Pengurus Cabang Nahdlatul Ulama" (PCNU) was created as a means of storing and managing data within the organization. There is a need for periodic website development and to maintain the quality of the website in each development, this research problem aims to measure the quality of the website owned by PCNU Depok. So that it can be assessed and made improvements to the next version of the website according to the needs of the organization's management. This study aims to measure the quality of the PCNU Depok website in terms of maintainability, flexibility and testability. The stages of the research carried out were: website module analysis, PCNU website installation, composer installation, PHPMetrics installation, running PHPMetrics application to measure PCNU website quality, analyzing measurement results from PHPMetrics. Research on website quality using the maintainability index method resulted in 63.57 which were classified as low maintainability values. The low maintenance index has an impact on the weakness of the module site for maintenance and development based on Lines Of Code, Cyclomatic Complexity, and Halstead Volume. Flexibility factor, the site gets a moderate classification or reasonable limit because it has coupling $=$ cohesion. Testability on the website has a good classification with an average value of 16.65. With a good testability value, the website gets a positive value in the testing and maintenance process so that the module is not difficult to understand and development.
\end{abstract}

Keywords - software metrics, maintainability index, flexibility, testability, PHPMetrics.

Abstrak-Website Pengurus Cabang Nahdlatul Ulama (PCNU) Depok dibuat sebagai sarana penyimpanan dan pengelolaan data dalam organisasi tersebut. Adanya kebutuhan pengembangan website secara berkala dan untuk menjaga kualitas website disetiap pengembangannya maka masalah tersebut penelitian bertujuan mengukur sejauh mana kualitas website yang dimiliki PCNU Depok. Sehingga dapat dinilai dan dilakukan perbaikan pada versi website selanjutnya sesuai dengan kebutuhan pengurus organisasi. Penelitian ini bertujuan untuk mengukur kualitas website PCNU Depok dilihat dari maintainability, flexibility dan testability. Tahapan penelitian yang dilakukan : analisis modul website, instalasi website PCNU, instalasi composer, instalasi PHPMetrics, menjalankan aplikasi PHPMetrics untuk mengukur kualitas website PCNU, menganalisis hasil pengukuran dari PHPMetrics. Penelitian kualitas website dengan metode maintainability index mehasilkan nilai 63,57 yang diklasifikasikan sebagai low maintainability. Low maintainibility index berdampak kepada lemahnya modul website untuk dilakukan perawatan dan pengembangan berdasarkan Lines Of Code, Cyclomatic Complexity, dan Halstead Volume. Faktor flexibility, website mendapatkan klasifikasi moderate atau batas wajar karena memiliki coupling = cohesion. Testability pada website memiliki klasifikasi baik dengan nilai rata-rata 16,65. Dengan nilai testability baik website mendapatkan nilai positip pada proses testing dan maintenance sehingga modul tidak sulit untuk dimengerti dan dikembangkan.

Kata Kunci- software metrics, maintainability index, flexibility, testability, PHPMetrics.

\section{PENDAHULUAN}

Salah satu faktor yang mempengaruhi kualitas suatu software dilihat dari Product Revision. Product Revision meliputi maintainibility, flexibility dan testability [1]. Pemeliharaan suatu software sangat penting dilakukan agar software / aplikasi tersebut terjaga kualitas dan performanya. Untuk mengukur tingkat performa software, dapat dilakukan proses pengujian dengan menggunakan perangkat lunak bantu (software tools) yang disesuaikan dengan bahasa pemrograman dari software yang akan dianalisis. Tingkat kualitas software berpengaruh kepada waktu maintenance dan biaya yang akan dikeluarkan dalam pengembangan ke versi selanjutnya [2]. Untuk melakukan pengukuran kualitas website khususnya pada bahasa pemrograman $P H P$, dapat digunakan tools analysis seperti PHP Depend, PHPloc, PHPmd, PHPMetrics dan lainnya. Tools tersebut menyajikan hasil analisis dalam berbagai format seperti format $\mathrm{html}, \mathrm{xml}$, bentuk tabel, grafik, dan format lainnya sesuai dengan tools dan perintah yang digunakan.

Beberapa penelitian terdahulu mengenai pengukuran kualitas software diantaranya adalah pengukuran kualitas website pada Kesharlindung Dikmen Kemendikbud dengan Automated Software Testing [3]. Penelitian lain dilakukan oleh Fikri yaitu pengukuran kualitas aplikasi pada Inventory Management Information System (SIMSEDIA) di SKPD Pekalongan [4]. Penelitian terdahulu lainnya adalah Perbandingan Maintainability, Flexibility, Testability pada CMS Open Source E-commerce [5]. Penelitian terdahulu mengenai Optimasi Maintainability Menggunakan Metode Clean Code Pada Sistem Informasi Museum Mandhilaras [6].

Tulisan ini membahas mengenai pengukuran kualitas website dari Pengurus Cabang NU Depok. Nahdlatul Ulama 
(NU) merupakan organisasi yang menegakkan ajaran Islam di tengah - tengah kehidupan masyarakat Negara Indonesia. Nahdlatul Ulama berusaha di bidang agama, pendidikan, sosial budaya dan usaha lainnya untuk membantu masyarakat Indonesia. Nahdlatul Ulama memiliki struktur kepengurusan yaitu Pengurus Besar (tingkat pusat), Pengurus Wilayah (tingkat provinsi), Pengurus Cabang (tingkat kabupaten/kota), Majelis Wakil Cabang (tingkat kecamatan), Pengurus Ranting (tingkat desa/kelurahan) [7]. Pengurus Cabang Nahdlatul Ulama Depok memiliki kegiatan mengelola keanggotaan cabang, pendataan masjid dan mushola dan kegiatan lainnya. Terkait kompleksitas dan keperluan pengolahan data tersebut dibutuhkan sistem informasi. Saat ini PCNU Depok telah memiliki website yang dapat diakses oleh masyarakat yang beralamat di www.nudepok.or.id. Sedangkan untuk kebutuhan pendataan internal dibuat sistem informasi berbasis website yang hanya dapat diakses oleh pengurus organisasi sesuai dengan kebutuhan dan wewenang anggota dengan alamat www.nukotadepok.com. Pada website Pengurus PCNU modul-modul yang tersedia meliputi modul Anggota Organisasi, Pengurus Organisasi dan Badan Otonom, Data Masjid dan Mushola, data Pondok Pesantren, data Panti Asuhan, data Majelis Ta'lim, data Ekonomi NU, data Penceramah dan modul pendukung lainnya. Aplikasi Sistem Informasi Manajemen PCNU Depok berbasis website dan dikembangkan dengan bahasa pemrograman $P H P$ menggunakan framework Codeigniter.masalah tambah disini Adapun pengukuran kualitas website PCNU yang akan diukur dibatasi pada modul controller, dimana tugas controller mengatur bagaimana HTTP request tersebut diproses, model maupun class dan fitur lain yang akan digunakan. Software tools yang digunakan dalam penelitian ini adalah PHPMetrics.

\section{TINJAUAN PUSTAKA}

\section{A. Software Quality Metrics}

Software Quality Metrics adalah pengukuran kualitas software dengan mencatat jumlah baris kode yang memiliki potensi kerusakan maupun kekurangan lainnya dan celah keamanan yang terdapat didalam software [8]. Data yang dihasilkan dari software quality metrics dapat digunakan untuk meningkatkan kualitas dan keefektifan proses pemrograman aplikasi. Berdasarkan dari data tersebut pihak developer dapat mengevaluasi hal - hal yang sebaiknya dilakukan maupun dihindari dalam proses pembuatan aplikasi [9]. Pengukuran dapat dilakukan disemua software untuk membantu mengestimasi, mengontorol kualitas, menilai produktivitas, mengontrol pekerjaan, membantu mengontrol kualitas produk dan mengambil keputusan dalam hasil pekerjaan pembuatan software [10].

\section{B. Maintainability Index}

Maintainability Index adalah software metric yang mengukur sebuah perangkat lunak dan aplikasi dalam aspek tingkat kesulitan aplikasi tersebut untuk dilakukan perawatan dan pengembangan di masa akan datang. Maintainability Index memiliki formula yang dihitung berdasarkan Lines of
Code (LOC), Cyclomatic Complexity (CC) dan Halstead Volume $(H V)[6]$. Formula yang digunakan secara umum :

$$
M I=171-5.2 \ln V-0.23 G-16.2 \ln L
$$

Sedangkan Formula yang digunakan pada PHPMetrics :

$$
\begin{gathered}
M I=171-5.2 \times \ln (H V)-0.23 \times(C C)- \\
16.2 \times \ln (L O C)+50 \times \sin (\operatorname{sqrt}(2.4 \times C L O C / L O C))
\end{gathered}
$$

Untuk pengelompokan hasil dari nilai maintainability index dapat dilihat pada tabel I.

Tabel I. Tabel Nilai Maintainability Index

\begin{tabular}{|c|l|}
\hline $\begin{array}{c}\text { Value of } \\
\text { Maintainability Index }\end{array}$ & \multicolumn{1}{c|}{ Classification } \\
\hline MI $<64$ & $\begin{array}{l}\text { Low maintainability status, project has a } \\
\text { critical or fatal technical error. }\end{array}$ \\
\hline MI $65-84$ & $\begin{array}{l}\text { Maintainability status, there are } \\
\text { problems / problems with the project but } \\
\text { not too serious. }\end{array}$ \\
\hline MI $>85$ & $\begin{array}{l}\text { High maintainability status, project } \\
\text { included in } \\
\text { good condition. }\end{array}$ \\
\hline
\end{tabular}

Deskripsi :

- $\quad \mathrm{MI}=$ Maintainability Index

- $\quad \mathrm{HV}=$ Halstead Volume

- $\mathrm{CC}=$ Cyclomatic Complexity

- $\quad \mathrm{LOC}=$ Line of code

- $\quad \mathrm{CLOC}=$ Comment Lines of Code

\section{FLEXIBILITY}

Flexibility mengacu kepada kapabilitas sebuah sistem, berdasarkan struktur sistem dan karakteristik pemrograman. Faktor ini bertujuan untuk menghitung tingkat kesulitan dan adaptasi sistem dalam pengembangannya jika ada perubahan yang dibutuhkan oleh pelanggan. Jika perubahan yang dilakukan dalam struktur sistem atau penambahan fungsi berdampak besar terhadap modul sistem yang lain, maka sistem tersebut dinilai kurang baik dalam faktor flexibility [11]. Klasifikasi tingkat flexibility dapat dilihat pada tabel II.

Tabel II. Tabel Kategori Flexibility

\begin{tabular}{|c|c|}
\hline Category & Classification \\
\hline Coupling $<$ Cohesion & Well \\
\hline Coupling $=$ Cohesion & Moderate \\
\hline Coupling $>$ Cohesion & Not good \\
\hline
\end{tabular}




\section{Testability}

Testability menjelaskan tentang tingkat keefektifan dan efisiensi dengan kriteria pengujian yang ditetapkan untuk suatu sistem, produk atau komponen pengujian dapat dilakukan untuk menentukan apakah kriteria tersebut telah terpenuhi [6]. Testability merupakan salah satu faktor yang menentukan waktu serta tingkat pekerjaan dalam pengujian aplikasi atau sistem [12]. Hasil dari analisis dapat diklasifikasi berdasarkan tabel III.

Tabel III. Tabel Kategori Testability

\begin{tabular}{|c|c|}
\hline Category & Classification \\
\hline Complexity $>10$ & Well \\
\hline Complexity $<10$ & Not good \\
\hline
\end{tabular}

\section{E. PHPMetrics}

PhpMetrics adalah aplikasi yang berfungsi untuk menghitung metric pada bahasa pemrograman PHP. PHPMetrics merupakan aplikasi open source yang dikembangkan oleh Jean-François Lépine dan mengakomodir beberapa metrics yang mengukur tingkat kompleksitas aplikasi, jumlah code atau variabel tertentu, data terkait object oriented, maupun tingkat maintainability. Metrics pengukuran berdasarkan kategori PHPMetrics adalah :

- Complexity: Cyclomatic complexity, Myer's interval, Relative system complexity

- Volume: Vocabulary, Data complexity, Lines of code, Readability

- Object Oriented: Lack of cohesion of methods, Coupling, Abstraction

- Maintainability: Maintainability index, Halstead's metrics, Effort.

\section{METODE PENELITIAN}

Pengukuran kualitas aplikasi pada website Pengurus Nahdlatul Ulama Depok memiliki beberapa bagian yaitu :

1. Tahap analisis modul website.

2. Menginstal website Sistem Informasi Manajemen Nahdlatul Ulama Depok pada perangkat yang akan digunakan untuk dilakukan analisis.

3. Melakukan instalasi tool testing PHPMetrics dengan mengikuti panduan instalasi pada halaman website : https://phpmetrics.org/ [13]. Gambar 1 merupakan contoh tampilan Composer pada terminal.

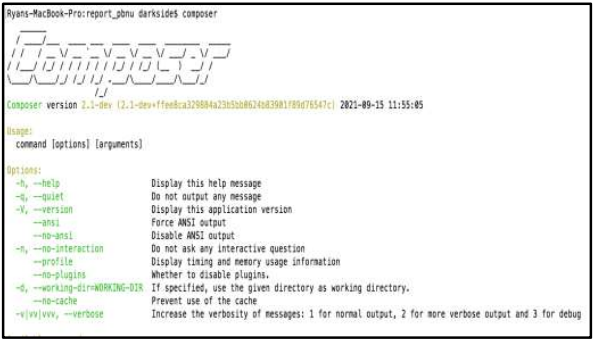

Gambar 1. Contoh Tampilan Composer pada Terminal

Setelah composer berhasil di instal pada perangkat yang telah ditentukan, tahap selanjutnya adalah proses instalasi PHPMetrics seperti pada Gambar 2.

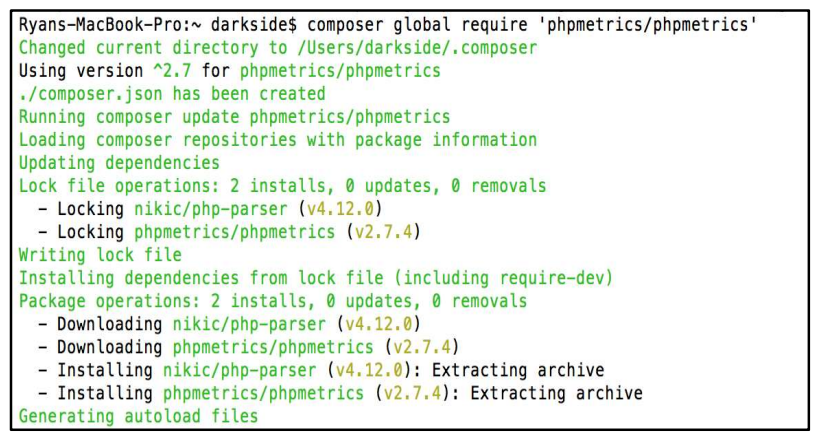

Gambar 2. Contoh Instalasi PHPMetrics Melalui Composer.

4. Menjalankan perintah PHPMetrics untuk mendapatkan hasil analisis kualitas website.

5. Menganalisis hasil laporan yang didapat dari aplikasi PHPMetrics.

\section{HASIL DAN PEMBAHASAN}

\section{A. Review Modul Website PCNU Depok}

Website Sistem Informasi Manajemen Nahdlatul Ulama Depok lebih bertujuan untuk menyimpan beberapa data yang terkait dengan organisasi. Data yang disimpan akan diolah menjadi informasi sesuai dengan modul dan kebutuhan organisasi. Informasi yang dihasilkan dapat digunakan sebagai penunjang keputusan dalam suatu kebijakan organisasi. Sistem Informasi Manajemen memiliki beberapa menu utama (Gambar 3) yaitu :

- Dashboard

- PCNU Depok

- Data Masjid

- Data Ponpes

- Data Panti Asuhan

- Data Majelis Ta'lim

- Data Ekonomi NU

- Data Penceramah

- Modul Data

- Modul Account 


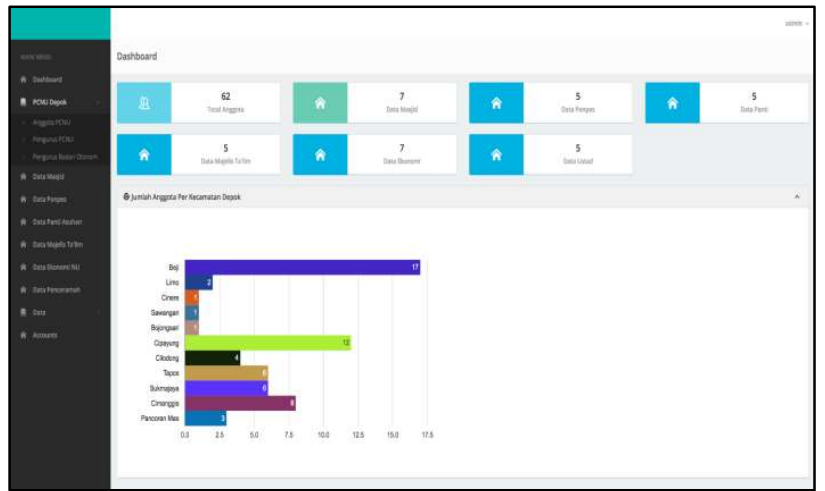

Gambar 3. Tampilan Halaman Dashboard

Menu PCNU Depok berisikan sub menu berupa menu Anggota, menu Pengurus PCNU, dan menu Pengurus Banom. Pada menu anggota, admin aplikasi dapat memasukkan data anggota sesuai dengan kategori yang telah ditentukan seperti nama, alamat dan data lainnya. Pada modul anggota, diperoleh kode anggota yang nantinya digunakan sebagai kode unik penanda keanggotaan dalam organisasi. Untuk menu kepengurusan PCNU maupun Banom, admin harus membuat struktur organisasi dan periode jabatan terlebih dahulu pada modul yang telah disediakan. Setelah konfigurasi struktur organisasi dan masa jabatan telah dilakukan, admin dapat mendata anggota organisasi yang dipilih dan dilantik oleh organisasi kedalam modul Pengurus PCNU maupun Pengurus Banom. Relasi modul Pengurus Organisasi maupun Pengurus Banom dapat dilihat pada Gambar 4.

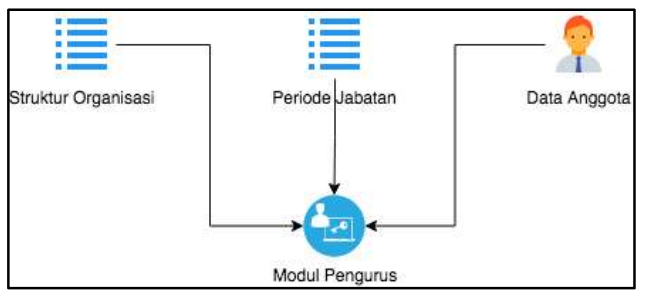

Gambar 4. Relasi Modul Pengurus

Menu Data Masjid berisikan modul yang mengakomodir data masjid maupun mushola yang terdapat di daerah Kota Depok. Modul ini mendata nama, alamat, dan informasi lainnya dalam aplikasi. Setelah data masjid atau mushola tersebut telah di data kedalam aplikasi, admin dapat menambahkan informasi pengurus masjid dan mushola pada modul Pengurus Masjid. Jika pengurus masjid atau mushola tersebut adalah anggota organisasi, admin dapat langsung memilih data anggota dalam kepengurusan masjid dan mushola yang diinginkan. Modul Pondok Pesantren merupakan modul yang berfungsi untuk mendata pesantren yang terletak di Kota Depok. Admin dapat mendata nama, alamat nomor telepon dan jumlah santri yang terdata di dalam suatu pondok pesantren. Setelah informasi pesantren telah didata, admin dapat menambahkan informasi anggota pengurus pondok pesantren di dalam modul pengurus pondok pesantren.
Modul pendukung organisasi lainnya adalah modul Panti. Modul Panti berisikan informasi mengenai nama, alamat, jenis panti, pengurus panti dan informasi lainnya yang dibutuhkan organisasi. Modul selanjutnya adalah modul Majelis Ta'lim. Modul Majelis Ta'lim bertujuan mendata informasi majelis seperti nama majelis dan kategori majelis maupun data pengurus majelis tersebut. Untuk mendukung terjalinnya komunikasi antara organisasi dan unit usaha Kota Depok, disajikan modul Ekonomi NU. Modul Ekonomi NU mendata jenis usaha maupun pemilik usaha tersebut. Modul pokok yang terakhir adalah modul Penceramah. Modul Penceramah berisikan informasi data penceramah atau ustad yang sebelumnya telah didata oleh organisasi. Di dalam modul data penceramah, pengguna website dapat melihat informasi nama, alamat, riwayat pendidikan serta informasi lainnya

\section{B. Class Controller}

Controller adalah inti dari website ini, yang dimana tugasnya untuk mengatur bagaimana HTTP request tersebut diproses. Gambar 5 menunjukan File Controller yang terdapat pada website.

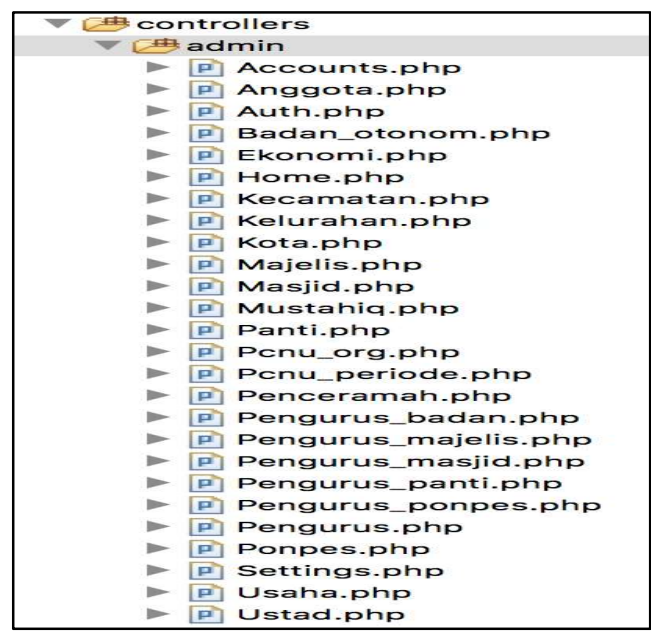

Gambar 5. Class Controller pada Website NU Depok

Pada controller terdapat beberapa public maupun private method yang mengatur http request. Controller tersebut berkomunikasi langsung dengan class model dan tampilan view yang akan ditampilkan kepada pengguna website.

\section{Menjalankan Aplikasi PHPMetrics}

Untuk mengukur tingkat kualitas software pada SIM NU Depok, digunakan tools PHPMetrics yang sebelumnya telah diinstall pada perangkat yang ditentukan. Contoh untuk menghasilkan report dari PHPMetrics adalah sebagai berikut:

Ryans - MacBook -

Pro: report_pbnu darkside\$ php ../vendor/bin/

phpmetrics - -report - html = myreport /

Applications/XAMPP/xamppfiles/htdocs/pbnu (3) 
Setelah perintah tersebut dijalankan, pada layar terminal akan tampil hasil dari analisis PHPMetrics (Gambar 6) dan membuat laporan sesuai dengan lokasi yang telah kita tentukan pada perintah tersebut.

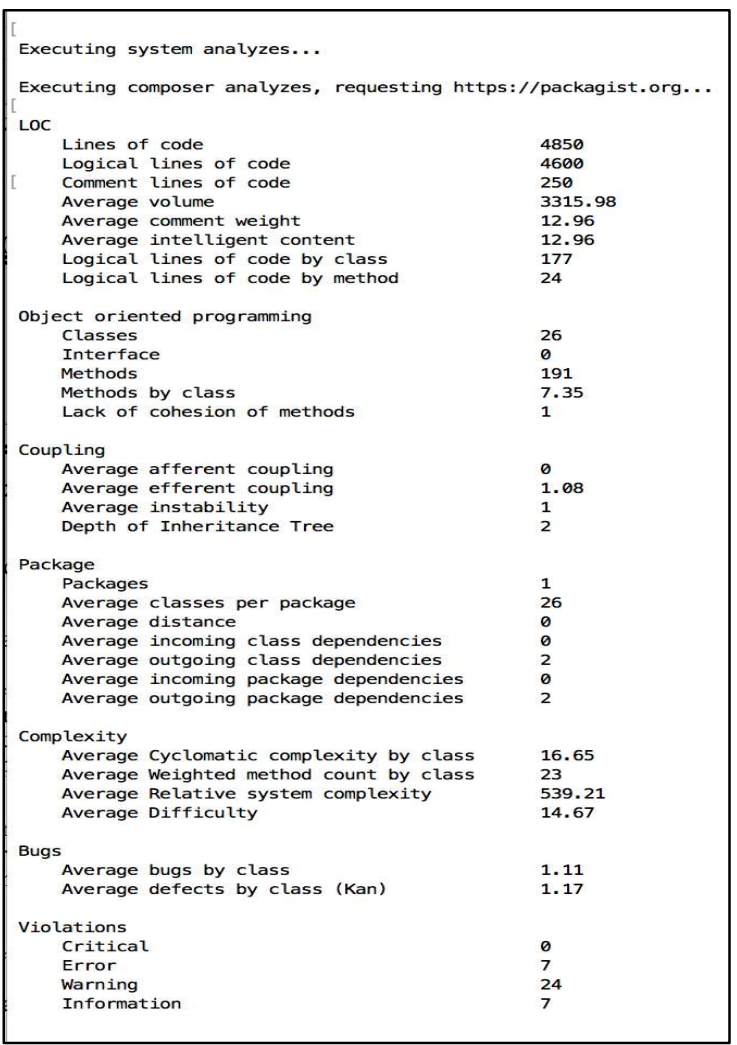

Gambar 6. Tampilan Hasil Analisis PHPMetrics pada Terminal

\section{Hasil Analisis Pengurkuran}

Fokus penelitian ini pada class controller yang terdapat pada website SIM PCNU NU Depok. Hasil dari tools metrics yang telah dijalankan pada website adalah sebagai berikut :

\section{Maintainability}

Setelah aplikasi PHPMetrics dijalankan, diperoleh data yang bisa di klasifikasikan ke faktor maintainability. Data hasil klasifikasi faktor maintainability dapat dilihat pada tabel IV.
Tabel IV. Tabel Maintainability Index modul controller

\begin{tabular}{|c|c|c|}
\hline $\begin{array}{c}\text { Value of } \\
\text { Maintainability } \\
\text { Index }\end{array}$ & $\begin{array}{c}\text { Number of } \\
\text { Class }\end{array}$ & Classification \\
\hline $\mathrm{MI}<65$ & 11 & $\begin{array}{c}\text { Low maintainability } \\
\text { status }\end{array}$ \\
\hline $65-84$ & 13 & Maintainability status \\
\hline $\mathrm{MI}>85$ & 2 & $\begin{array}{c}\text { High maintainability } \\
\text { status }\end{array}$ \\
\hline Average & $\mathbf{6 3 , 5 7}$ & $\begin{array}{c}\text { Low maintainability } \\
\text { status }\end{array}$ \\
\hline
\end{tabular}

Di dalam modul controller terdapat 26 class controller yang dilakukan uji coba menggunakan PHPMetrics. Diperoleh hasil 11 class controller memiliki index $\mathrm{MI}<65$ atau masuk ke klasifikasi Low maintainability status. Sedangkan 13 class controller dengan index 65-84 yaitu maintainability status. Dan untuk klasifikasi high maintainability status terdapat 2 class controller. Jika diratarata dari keseluruhan Maintainability Index, modul controller memiliki nilai 63,57 yang merupakan klasifikasi low maintainability status.

\section{Flexibility}

Faktor pengukuran kualitas software menggunakan metric flexibility pada modul controller mendapatkan hasil coupling measurements $=$ cohesion measurement. Hal tersebut dihasilkan karena jumlah coupling rata-rata yang dihasilkan adalah 1 dan cohesion rata-rata adalah 1. Disimpulkan bahwa nilai perbandingan rata-rata coupling dan cohesion adalah 1 : 1.

Tabel V. Tabel flexibility modul controller

\begin{tabular}{|c|c|c|}
\hline Category & Number of Class & Classification \\
\hline Coupling $<$ Cohesion & 0 & Well \\
\hline Coupling $=$ Cohesion & 26 & Moderate \\
\hline Coupling $>$ Cohesion & 0 & Not good \\
\hline Average & $\begin{array}{c}\text { Coupling }= \\
\text { Cohesion }\end{array}$ & Moderate \\
\hline
\end{tabular}

Pada tabel V dapat dilihat bahwa seluruh class controller yang dilakukan analisis coupling dan cohesion memiliki nilai yang sama. Yang berarti dalam faktor flexibility, aplikasi masih dalam batas wajar. Sehingga untuk pengembangan website, team pengembang tidak memiliki kendala besar dalam penyesuaian modul dan website sesuai dengan kebutuhan pengguna. Namun hal lain seperti dokumentasi 
website maupun dokumen pelengkap lain penunjang website harus secara lengkap dideskripsikan untuk memudahkan pembuat website di proses pengembangan selanjutnya.

\section{Testability}

Testability metric merupakan salah satu faktor penentu kualitas suatu aplikasi yang ditentukan oleh tingkat kesulitan aplikasi tersebut pada tahap pengujian atau testing. Semakin rendah nilai testability berarti aplikasi tersebut semakin sulit untuk dilakukan pengujian dan maintenance. Hasil PHPMetrics yang telah dianalisis dapat diklasifikasikan untuk mendapatkan tingkat testability dari website. Hasil klasifikasi testability dapat dilihat pada tabel VI.

Tabel VI. Tabel testability modul controller

\begin{tabular}{|c|c|c|}
\hline Category & Number of Class & Classification \\
\hline Complexity $>10$ & 9 & Baik \\
\hline Complexity $<10$ & 17 & Tidak Baik \\
\hline Average & $\mathbf{1 6 , 6 5}$ & Baik \\
\hline
\end{tabular}

Setelah dilakukan analisis, dari 26 class dihasilkan 9 class memiliki complexity $>10$ dan 17 class mendapatkan kategori complexity $<10$. Hasil nilai rata-rata complexity dari 26 class adalah 16,65 yang dapat diklasifikasikan Baik dalam faktor testability.

\section{KESIMPULAN}

Berdasarkan dari hasil pengukuran dan pengolahan data yang didapat dari PHPMetrics, telah dilakukan klasifikasi berdasarkan faktor Maintainability Index, Flexibility dan Testability. Faktor maintainability index nilai low maintainability status dengan nilai 63,57. Nilai maintainibility index dengan status low maintainability berpotensi rendah nya tingkat pemeliharaan maupun pengembangan website.

Sedangkan untuk faktor flexibility, modul controller mendapatkan nilai rata-rata coupling $=$ cohesion . Berdasarkan nilai rata-rata flexibility tersebut dapat diklasifikasikan bahwa modul tersebut memiliki batas wajar. Batas wajar flexibility berdampak positif kepada proses pengembangan website sesuai dengan kebutuhan. Ketika ada kebutuhan tertentu baik penambahan proses bisnis maupun modul tertentu, modul controller yang terdapat dalam website PCNU Depok dapat beradaptasi dengan baik terhadap kebutuhan dan perubahan tersebut. Hal itu disebabkan tingkat keterkaitan class controller tidak terlalu tinggi. Sehingga jika ada penambahan maupun perubahan, tidak berdampak besar pada class controller yang telah ada.

Faktor selanjutnya adalah testability yang memiliki nilai rata-rata 16,65 dengan klasifikasi baik dalam faktor tersebut. Klasifikasi baik dalam faktor testability berpotensi positif dalam aspek testing dan maintenance website.
Berdasarkan hasil pengukuran kualitas website pada maintainibility index terdapat potensi rendahnya tingkat pemeliharan dalam proses pengembangan website. Disarankan pada proses pengembangan website selanjutnya dapat ditingkatkan pada bagian tersebut. Dan sebaiknya pengukuran kualitas website dilakukan secara berkala agar kualitas website dapat terus terjaga dengan baik.

\section{UCAPAN TERIMAKASIH}

Ucapan terima kasih kepada Universitas Gunadarma, Rektor, Dekan, Kaprodi, Dosen MMSI dan Ibu Karmilasari yang telah membimbing dan mengarahkan penulis sehingga dapat menyelesaikan penelitian mengenai Pengukuran Kualitas Website Pengurus Cabang NU Depok Menggunakan Software Metrics. Dan begitu besar hutang budi penulis kepada kedua orang tua Muslih Nawawi dan Aida Sari, istri tercinta Bertha Desnalia serta putra dan putri penulis yang selalu mendukung dan menemani penulis sehingga dapat memberikan hasil terbaik dalam penelitian ini.

\section{REFERENSI}

[1] McCall, J. A., Richards, P. K., \& Walters, G. F. (1977). "Factors in software quality. volume i. concepts and definitions of software quality". GENERAL ELECTRIC CO SUNNYVALE CA.

[2] Abdullah, Abdullah, Dr. M.H. Khan, Dr. Reena Srivastava.(2015)."Flexibility: A Key Factor to Testability". Int. J. Softw. Eng. Appl., vol. 6, no. 1, pp. 89-99.

[3] Dakroni, Dakroni, Karmilasari, Karmilasari. (2020). "Measurements of Application Revision Quality at Kesharlindung Dikmen Application Website of the Ministry of Education and Culture Using Automated Software Testing”. Universitas Gunadarma.

[4] Fadlillah, Fikri. (2016). "Software Quality Measurement of Inventory Management Information System (SIMSEDIA) on Local Government Agency (SKPD) of Pekalongan". Universitas Gunadarma.

[5] Anggrainingsih, Rini., Suryoni, Aren Dwipa Pangestuti., Rohmawat, Umu Amanah Nur. (2017). "Perbandingan Maintainability, Flexibility, Testability pada CMS Open Source E-Commerce". Universitas Sebelas Maret.

[6] Hadiansyah, Farhan. (2019). "Optimasi Maintainability Menggunakan Metode Clean Code pada Sistem Informasi Museum Mandhilaras". Universitas Komputer Indonesia.

[7] Nahdlatul Ulama. (2021). Struktur Organisasi. Diakses pada 20 September 2021, dari https://www.nu.or.id/static/12/struktur-organisasi

[8] ProfesionalQA. (2021). Sofware Quality Metrics. Diakses pada 20 September 2021, dari https://www.professionalqa.com/software-qualitymetrics

[9] Nystedt, Sofia., Sandros, Claes. (1999). "Software Complexity and Project Performance". School of Economics and Commercial Law at the University of Gothenburg.

[10] Susanto, M. I., Darwiyanto, E., \& Wisudawan, G. A. 2015. Pengukuran Software Metrics Terhadap Implementasi Framework Laravel pada Pembangunan Aplikasi Berbasis Web . e-Proceeding of Engineering, 7731-7738.

[11] Software Quality Assurance, Daniel Galin, Pearson Education Limited 2004

[12] Khan, M. H and Srivastava, R. (2015). "Testability Measurement Model for Object Oriented Design (TMMOOD)".

[13] J.-F. Lépine, "Metrics of PhpMetrics," phpmetrics.org, 2021. Diakses pada $20 \quad$ September $2021, \quad$ dari http://www.phpmetrics.org/documentation/index.html 